\title{
giFORSETI
}

Forseti. Revista de Derecho. Volumen 11, № 15, Lima, 2022, pp. 63-91

\section{La Business Judgment Rule (BJR) en el Perú: ¿Es necesaria su inclusión en el Derecho Societario peruano?}

\author{
Jesús Hernández Peña*
}

Resumen. - La Business Judgment Rule es una regla que ha sido introducida en el texto del Anteproyecto de la Ley General de Sociedades con la finalidad de proteger la discrecionalidad empresarial de los directores y gerentes de las sociedades anónimas peruanas. En el siguiente ensayo analizaremos normativa y jurisprudencia comparada con el fin de constatar su necesidad y compatibilidad con nuestro sistema jurídico de responsabilidad civil.

\begin{abstract}
The Business Judgment Rule is a rule that has been introduced in the text of the Draft Bill of the General Corporations Law with the purpose of protecting the business discretion of the directors and managers of Peruvian corporations. In the following essay we will analyze comparative regulations and jurisprudence to verify its necessity and compatibility with our civil liability legal system.
\end{abstract}

Palabras claves. - Business Judgment Rule - Responsabilidad civil - AdministradoresDeberes fiduciarios- Diligencia.

Keywords. - Business Judgment Rule - Tort Liability - Administrators - Fiduciary duties Diligence.

* El autor es abogado por la Pontificia Universidad Católica del Perú (PUCP) y cuenta con una especialización en Responsabilidad Civil por la Universidad de Castilla-La Mancha, España. Asimismo, tiene un Diplomado en Arbitraje por la Universidad Austral de Buenos Aires y, actualmente, está cursando la Maestría en Derecho de la Empresa de la Escuela de Posgrado de la PUCP. Es abogado asociado del área de competencia y arbitraje de BuenoLercari Consultores y ha sido autor de publicaciones relacionadas a temas contractuales y arbitraje. 


\section{Introducción}

Una de las características principales de la Sociedad Anónima es la administración delegada. En tanto se busca reducir los costos de transacción de la toma de decisiones ${ }^{1}$, los accionistas (principal) delegan la administración de la sociedad a un grupo determinado de individuos (agentes), quienes se obligan a actuar en favor de los intereses de la sociedad. Los problemas en esta relación, no obstante, ocurren cuando el agente tiene intereses distintos a los del principal y, en virtud de ello, actúa en desmedro del interés del cual es llamado a proteger. La existencia de estos problemas, llamados por la doctrina como problemas de agencia, ocasiona que el derecho societario establezca una serie de medidas preventivas para fiscalizar la actividad de los directores y gerentes, previniendo de esta manera cualquier acto contrario al interés social.

Desde esta óptica, y sin perjuicio de la existencia de otras estrategias jurídicas, una de las formas en que el derecho societario limita la actividad de los directores y gerentes es mediante la imposición de deberes de buena fe, diligencia y lealtad en el ejercicio de sus funciones. Esto último, sin embargo, no resuelve el problema del todo, ya que abre una serie de nuevas incógnitas referidas a la forma en que se debería imputar responsabilidad civil a dichos agentes por el incumplimiento de estos deberes; siendo que dichas dudas se incrementan en aquellos casos donde las decisiones empresariales han generado resultados negativos para la sociedad.

En ese sentido, ¿un director o gerente debería ser responsable civilmente por los resultados negativos de su gestión? ¿Se estarían incumpliendo los deberes de diligencia, buena y/o lealtad cuando la gestión empresarial no arroja resultados positivos?

Pese a que la respuesta a estas preguntas tiene incidencia directa en el nivel de riesgo que los directores y gerentes están dispuestos a asumir, las mismas no han sido tratadas en la jurisprudencia y normativa nacional. Esta situación motivó que el Grupo de Trabajo que se encargó de la redacción del Anteproyecto de la Ley General de Sociedades (ALGS), incluyera en su art. 154, la regla de protección de la discrecionalidad empresarial o Business Judgment Rule (BJR). Nacida en Estados Unidos, la BJR se fundamenta en una premisa simple: en la medida que el director o gerente haya actuado de forma diligente y de buena fe, el juez no cuestionará el criterio económico empleado ni tendrá en cuenta las consecuencias económicas de las operaciones realizadas para imputar responsabilidad civil. Esta

1 Sobre el particular, John Armour, Henry Hansmann y Reinier Kraakman señalan lo siguiente: "Third, though largely or entirely chosen bu the firm's shareholders, the board is formally distinct from them. This separation economizes on the costs of decision-making by avoiding the need to inform the firm's ultimate owners and obtain their consent for all but the most fundamental decisions regarding the firm." En ARMOUR, J., HANSMANN H. y KRAAMAN, R. "What is Corporate Law?". The Anatomy of Corporate Law. A comparative and functional approach. New York: Oxford University Press, p. 14, 2009. 
regla permite proteger la discrecionalidad empresarial y, en contrapartida, hace más objetivo el control de la gestión social por parte de los accionistas.

Si bien la inclusión de esta regla es positiva desde un punto de vista teórico, subyace la pregunta respecto a si dicha regla es compatible con nuestro sistema legal. Ciertamente, no podemos olvidar que los orígenes y el desarrollo de la BJR se dieron en una cultura jurídica distinta a la nuestra, lo cual hace que las normas societarias y el sistema de responsabilidad civil no sean necesariamente iguales a los nuestros.

Sin perjuicio de lo anterior, también debemos responder una segunda pregunta de similar importancia: ¿Es realmente necesaria la inclusión de la BJR en nuestra legislación societaria? Como toda regulación, la Ley General de Sociedades (LGS) y el ALGS deben resolver aquellos problemas que efectivamente se dan en el seno de las sociedades peruanas, por lo que la inclusión de la BJR debe responder a una necesidad debidamente acreditada y no a un mero capricho del legislador. Caso contrario, se corre el riesgo que la BJR devenga en ineficaz.

El presente artículo, por ende, busca responder a las preguntas anteriormente planteadas, para lo cual dividiremos el texto en tres (3) partes. La primera parte estará destinada a analizar la BJR, sus fundamentos y requisitos de aplicación. En la segunda parte, nos enfocaremos en revisar cómo es que se encuentra legislado el sistema de responsabilidad civil de los directores y gerentes en nuestro país para, en la tercera parte, desarrollar los argumentos que, consideramos, justificarían la incorporación de la BJR a nuestra legislación societaria.

Cabe resaltar que la BJR es una regla aplicable a los directores y gerentes por igual, por lo que a lo largo del texto se hará referencia a todos estos como "administradores". Asimismo, el análisis se enfocará únicamente en los administradores de una Sociedad Anónima, por lo que no desarrollaremos la aplicación de la BJR a otros tipos de sociedades.

\section{La Business Judgment Rule (BJR)}

La Business Judgment Rule (BJR) es una regla jurisprudencial que, bajo la premisa que los administradores han actuado de forma diligente, evita la revisión de los resultados económicos de sus decisiones a efectos de imputarles responsabilidad civil. De esta forma, no se analiza el resultado de la actividad del administrador, sino que se evalúa si el mismo ha actuado en forma diligente al momento de tomar una determinada decisión empresarial.

Para Francisco Reyes Villamizar, la BJR es una regla que reconoce la discrecionalidad de los administradores al momento de tomar sus decisiones económicas:

“Las cortes norteamericanas han preferido no inmiscuirse en el análisis económico de las decisiones administrativas de la sociedad. Es por ello por lo que han adoptado la denominada regla de la discrecionalidad ("Business 
Judgment Rule"), en cuya virtud los administradores son autónomos en la toma de sus determinaciones, siempre y cuando estas obedezcan a un raciocinio adecuado a las circunstancias." 2

Esta regla, por ende, funge de límite al análisis jurisprudencial de la responsabilidad civil de los administradores, en tanto hace que sólo se tenga en cuenta la actividad humana (como debería ser) que desembocó en la decisión empresarial y no los resultados negativos de dicha decisión ni el criterio económico empleado.

Ahora bien, para entender mejor cómo es que se aplica la BJR, importa revisar sus antecedentes jurisprudenciales en el derecho anglosajón.

\section{i. Antecedentes y fundamento}

Antes de desarrollar este extremo del análisis, corresponde precisarle al lector algunos aspectos importantes del derecho societario anglosajón. Así pues, las normas societarias estadounidenses son promulgadas por cada Estado, siendo que el gobierno federal, en principio, sólo tiene competencia para regular aquellos temas relacionados con las sociedades cotizadas en bolsa ${ }^{3}$. Esta situación le permite a las empresas estadounidenses elegir donde registrarse y constituirse, por lo que cada Estado "compite" por ver quién le ofrece mejores condiciones regulatorias a dichos agentes económicos. Esto es llamado por la doctrina como "mercado de leyes".

Teniendo en cuenta que la principal fuente de derecho del Common Law es la jurisprudencia, las cortes estatales, que resuelven las controversias societarias que se dan en las sociedades inscritas en sus respectivas jurisdicciones, tienen la importante tarea de interpretar las normas societarias a fin de brindarles seguridad jurídica a los empresarios respecto a la forma en que se resolverán sus controversias legales. Esto último permite que la legislación societaria se desarrolle y responda a las nuevas necesidades del mercado ${ }^{4}$.

En este contexto, la BJR nace como parte de la competencia entre Estados por captar la inversión privada, brindando una pauta de solución a los problemas de agencia administrador-accionista que, posteriormente, sería replicada a lo largo de los Estados Unidos. Así pues, su caso más emblemático fue Otis \& CO. vs Pennsylvania R.CO. (1945), el cual se resolvió en Pennsylvania y donde se dilucidó la responsabilidad civil de los directores de la empresa Pennsylvania R. CO. por la "mala" negociación de bonos financieros que devino en una pérdida de

2 REYES VILLAMIZAR, Francisco. El Derecho Societario en Estados Unidos: Introducción Comparada. Bogotá: Legis, 2006, p. 188-189.

3 REYES VILLAMIZAR, Francisco. Ibid. p. 77.

4 SOLOMON, L. \& PALMITER, A. Corporations, examples and explanations, Segunda Edición, Boston: Little Brown and Company, 1994, p.40. 
US\$1`000,000 para la compañía. Los hechos del caso son como siguen, los cuáles han sido tomados de la misma sentencia5.

En 1943, Pennsylvania, Ohio and Detroit RR Co. (en adelante, PO\&D) decidió emitir bonos con un interés de $4.5 \%$, el cual iba a ser garantizado por su accionista mayoritario, Pennsylvania RR Co. (en adelante, PRR). Entre mayo y los primeros días de junio de 1943, Kuhn, Loeb \& Co. (KLC) entabló una serie de negociaciones con PRR para adquirir dichos bonos, lo cual culminó en un acuerdo no vinculante. Posteriormente, Halsey, Stuart \& Co. y Otis \& Co. (HSC y OC) solicitaron a PO\&D la posibilidad de realizar una oferta por los bonos previamente adjudicados; solicitud que fue rechazada por el Sr. Celement y el Sr. Pabs, administradores de PO\&D.

La reiterada negativa de los directores de PO\&D motivó a sus accionistas a demandarlos por responsabilidad civil derivada de presuntos incumplimientos a su deber de cuidado y juicio ordinarios ya que, de haberse aceptado la oferta realizada por HSC y OC, PO\&D hubiese ganado US\$1`000,000 más que el trato primigeniamente cerrado.

Al momento de resolver este caso en la Corte Distrital del Este de Pennsylvania, el Juez Kalodner precisó que los directores no eran responsables por los errores económicos incurridos en un desarrollo honesto del negocio, entendido ello como una expresión del principio de buena fe:

"In disposing of the case under the New York Law, the concept familiarly known as the "business judgment rule" was applied by the court, 49 N.Y.S.2d at page 643:

The question is frequently asked, how does the operation of the so-called 'business judgment rule' tie in with the concept of negligence? There is no conflict between the two. When the courts say that they will not interfere in matters of business judgment, it is presupposed that judgment reasonable diligence has in fact been exercised. A director cannot close his eyes to what is going on about him in the conduct of the business of the corporation and have it said that he is exercising business judgment. Courts have properly decided to give directors a wide latitude in the management of the affairs of a corporation provided always that judgment, and that means an honest, unbiased judgment, is reasonably exercised by them.

(...) In any event, it is well settled that what constitutes negligence depends upon the circumstances of the case; that the court will not interfere with the internal management of corporations, and therefore will not substitute its judgment for that of the officers and directors; and what is a rule of reason,

5 La sentencia puede consultarse en el siguiente link: https://law.justia.com/cases/federal/district-courts/FSupp/61/905/1607268/. 
that negligence must be determined as of the time of the transaction. It is also clearly established that mistakes or errors in the exercise of honest business judgment do not subject the officers and directors to liability for negligence in the discharge of their appointed duties" (el enfasis es nuestro)

Como vemos, el criterio jurisprudencial se inclinó por centrar el análisis de responsabilidad civil en la diligencia de los administradores y no en los efectos económicos de sus actos, estableciéndose que estos sólo serían responsables si es que se lograse acreditar su negligencia. Este criterio jurisprudencial fue replicado en el caso Aronson v Lewis (1984), donde los jueces de la Corte Suprema de Delaware resolvieron lo siguiente:

"It is a presumption that in making a business decision the directors of a corporation acted on an informed basis, in good faith and in the honest belief that the action taken was in the best interests of the company. Absent an abuse of discretion, that judgment will be respected by the courts. The burden is on the party challenging the decision to establish facts rebutting the presumption." 6

De esta manera, la BJR fue aplicada como una presunción de actuación de buena fe en favor de los administradores, siendo que los jueces únicamente imputaban responsabilidad civil si los demandantes lograban probar lo contrario en cada caso concreto.

Posteriormente, la jurisprudencia norteamericana precisó que la función principal de la BJR era la preservación de las decisiones económicas realizadas al interior de la empresa. Si bien esta función ya estaba implícitamente reconocida desde su nacimiento, los jueces empezaron a reconocer expresamente que la BJR evitaba que los demandantes cuestionen el criterio comercial de los administradores para solicitar el pago de una indemnización. Esto, por ejemplo, fue precisado por el Juez Wells de la Corte de Apelaciones de North Carolina en la sentencia Alford v Shaw de 19887:

"The rule (Business Judgment Rule) simply means that courts, honoring principles of corporate self-government, will not inquire into good faith decisions involving business judgment; directors not being liable for mere mistakes of judgment. It is well established that where a corporation, pursuant to a good faith business decision by the board of directors, elects not to pursue a claim upon demand, the business judgment rule prevents a

6 La sentencia puede revisarse en el siguiente link: https://law.justia.com/cases/delaware/supreme-court/1984/473-a-2d-805-4.html.

7 La sentencia se puede revisar en el siguiente link: https://casetext.com/pdfdownloaded?download_redirect $=$ alford $-\mathrm{v}-$ $\underline{\text { shaw\&utm_source }=I t e r a b l e \& u t m \_ \text {medium }}=$ email\&utm_campaign=PDF-emails 
shareholder from substituting his or her judgment by initiating a derivative action"

La BJR, por ende, fue concebida como un mecanismo para proteger el criterio económico de los administradores, garantizándoles que sus decisiones no generarían responsabilidad civil en la medida que fueran diligentes. De allí que su aplicación haya sido muy difundida en las cortes anglosajonas desde aquél entonces.

Tal es el ámbito de aplicación de la BJR que la misma, incluso, fue aplicada a casos donde se discutía la diligencia del directorio al momento de contratar personal clave de la empresa. Esto ocurrió en el caso Brehm et al v. Eisner and the Walt Disney Company (Caso Disney del 2000), donde los accionistas demandaron a Michael Eisner y sus directores por la negativa contratación de Michael Ovitz como su gerente principal. Sin perjuicio de la complejidad fáctica del asunto, basta decir que el caso giró en torno a determinar si Eisner y los demás directores fueron diligentes al momento de contratar a Michael Ovitz y, a su vez, si actuaron de buena fe al incluir una "goldenparachute" 8 en su contrato.

En este caso, la Corte Suprema de Delaware9 estimó que la decisión de contratar a Ovitz estaba dentro del ámbito de aplicación de la BJR, siendo que los demandantes no habían probado que Eisner y los demás directores habían actuado de mala fe y en forma desinformada en su contratación. Respecto a la cláusula "goldenparachute", la corte estimó que estos pactos eran comunes en el mercado y no era posible calificar si la misma era idónea o no para las transacciones comerciales, ya que también estaba protegida por la BJR.

De esta manera, no cabe duda de que esta regla alcanza a todo tipo de decisiones empresariales, protegiendo el criterio económico de los administradores en el manejo de la empresa, siempre y cuando se advierta que hayan actuado en forma diligente y de buena fe.

\section{ii. Definición}

Como ya lo adelantamos, la BJR es aquel método que emplean los jueces para decidir si los administradores han incurrido, o no, en actos que merecen la imputación de responsabilidad civil. Al respecto, Lori McMillan define a la Business Judgment Rule de la siguiente forma:

"The Business Judgment Rule ensures that decisions made by directors in good faith are protected even though, in retrospect, the decisions prove to

8 Dicha cláusula le otorgó a Ovitz el derecho a percibir una indemnización cuantiosa en caso que Disney prescindiera de sus servicios; situación que ocurrió un (1) año después de su contratación.

9 La sentencia se puede revisar en el siguiente link: https://casetext.com/pdfdownloaded?download_redirect $=$ brehm-veisner\&utm_source=Iterable\&utm_medium $=$ email\&utm_campaign=PDF-emails 
be unsound or erroneous. It provides a deference to prevent courts form second-guessing business decisions that were made in good faith."10

De esta definición podemos advertir que la BJR se relaciona con otros dos (2) conceptos fundamentales: la buena fe y la debida diligencia. Tal y como hemos visto, la jurisprudencia anglosajona aplica la BJR sólo en casos donde los administradores han actuado de forma diligente y de buena fe, ya que se busca incentivar la correcta realización de los negocios y no encubrir decisiones negligentes. Es por ello que coincidimos con Felipe Suescún cuando señala que “(...) la BJR (...) protege a administradores "desinteresados", esto es, aquellos que no sean parte de la transacción ni que puedan esperar que se derive para ellos un beneficio económico; que la regla únicamente es aplicada para decisiones que hayan sido tomadas con la debida información, de manera que los administradores tienen la obligación de considerar lo siguiente:

"toda la información material razonablemente a su alcance"; que la regla no está destinada a proteger a administradores que han cesado en sus funciones o que no hayan actuado de buena fe; (...) que la regla aplica cuando los administradores actúan con la debida diligencia, la cual es la medida con el estándar de la culpa grave, no la simple negligencia (...)." 11

Así pues, la BJR no busca otorgarle una discrecionalidad absoluta al administrador en el ejercicio de sus funciones, sino que delimita objetivamente cuáles serán las pautas que un juez seguirá al momento de analizar la diligencia del mismo por ocasión de una demanda de daños y perjuicios. Se trata de un límite objetivo entre la negligencia del administrador y el criterio económico empleado por aquél en la gestión empresarial; límite que se hace de suma importancia si advertimos que el riesgo connatural del mercado hace que la línea divisoria entre uno $u$ otro sea difusa.

En efecto, no podemos olvidar que el mercado lleva intrínsecamente aparejado una serie de riesgos que no podrán evitarse y que pueden determinar el éxito o fracaso de una decisión económica. Riesgos cuya naturaleza e intensidad, tal y como lo señala Pietro Trimarchi, variará dependiendo de la industria que analicemos.12 De allí que siempre existirá la posibilidad que una determinada decisión económica devenga en un "mal negocio" para la empresa, lo cual no sólo dependerá del nivel de diligencia empleado por sus administradores, sino también de otros factores económicos que son ajenos a la voluntad de estos (alza de precios de las materias primas o la baja de la cotización accionaria de la bolsa de valores, por ejemplo).

10 MCMILLAN, Lori. “The Business Judgment Rule as an immunity doctrine”. En William \& Mary Business Law Review N $N^{\circ}$ 21, 2013, p. 526-527.

11 SUESCÚN DE ROA, Felipe. “The business judgment rule en los estados unidos: una regla con dimensión procesal y fuerza sustantiva". En Vniversitas N"127, Bogotá, 2013, p. 347 - 348.

12 TRIMARCHI, Pietro. “Riesgo y Responsabilidad Objetiva”. Traducción de Leysser León Hilario, p. 2. 
Desde esta óptica, los administradores siempre toman decisiones económicas riesgosas, por lo que el análisis de su diligencia debería tener en cuenta el nivel de información consultada y la buena fe empleada, y no los resultados de la decisión ni la idoneidad del criterio económico empleado. Lo contrario sería exigirles a los administradores que revisen la idoneidad de su comportamiento y controlen otros factores económicos ajenos a su voluntad; exigencia que, como lo señala Jose Antonio Payet, únicamente ocasionaría consecuencias negativas al desarrollo económico de la compañía. En palabras del referido autor:

“En el caso del deber de diligencia, una regla de responsabilidad excesivamente severa tiene una alta probabilidad de conducir a un resultado indeseado por los propios accionistas. (...) [U]na regla de este tipo puede generar sobrecumplimiento, en el sentido que buscando evitar una posible responsabilidad los administradores dejen de asumir incluso riesgos empresariales razonables. Además, existe una clara ventaja relativa de los administradores por encima de los jueces para decidir cuándo una determinada decisión o conducta es razonable desde el punto de vista empresarial, por lo que la revisión judicial de esas decisiones resulta inconveniente."13

Es por ello por lo que la BJR representa un gran apoyo para los administradores y el tráfico económico en el mercado, por cuanto evita que los resultados del negocio y la idoneidad del criterio económico empleado sean elementos determinantes para imputar responsabilidad civil.

\section{iii. Requisitos para aplicar la BJR}

La doctrina y la jurisprudencia coinciden en identificar cuatro (4) requisitos para la aplicación de la BJR: (i) que el administrador haya tomado la decisión de buena fe; (ii) que no exista un interés personal en la operación; (iii) que se haya tenido en cuenta toda la información disponible $y$, (iv) que se haya cumplido con el procedimiento de decisión aplicable14 15. Por lo tanto, en la medida que los administradores cumplan estos requisitos, se entenderá que los mismos han sido diligentes y el juez no tendrá razón para imputarles responsabilidad civil por los malos resultados de su gestión.

Estos requisitos han sido legislados de múltiples formas en todas las jurisdicciones que han incluido a la BJR en sus normativas societarias. En España, por ejemplo, el legislador incluyó dichos requisitos en el art. $226^{\circ}$ de la Ley de Sociedades de

13 PAYET, Jose Antonio. “Empresa, Gobierno Corporativo y Derecho de Sociedades: Reflexiones sobre la protección de las minorías". THEMIS-Revista de Dererecho, núm. 46, Lima, 2003, p. 87.

14 GURREA-MARTÍNEZ, Aurelio. Op. Cit. p. 418.

15 GUERRA, Alberto. La Business Judgment Rule, un balón de oxígeno para el riesgo en las decisiones estratégicas. Fecha de consulta: 12 de abril del 2021.

https://www.garrigues.com/es_ES/noticia/la-business-judgement-rule-un-balon-de-oxigenopara-el-riesgo-en-las-decisiones-estrategicas 
Capital de España ${ }^{16}$ a fin de proteger la discrecionalidad empresarial de los administradores, siendo que dicho texto ha servido de insumo para la redacción del art. $154^{\circ}$ del ALGS peruano. Así pues, el texto español y el texto peruano son casi iguales con la salvedad que el legislador peruano fue más enfático en señalar que la BJR libera de responsabilidad civil a los administradores aun cuando los resultados de su gestión sean negativos para la compañía, tal y como se ve a continuación:

“Artículo 154.- Protección de la discrecionalidad empresarial en el ejercicio del cargo

154.1 En el ámbito de las decisiones estratégicas y de negocio, sujetas a la discrecionalidad de los directores, los niveles requeridos de diligencia se entenderán cumplidos cuando el director haya actuado de buena fe, sin conflicto de interés en el asunto objeto de decisión, con información razonablemente suficiente

según las circunstancias y siguiendo un procedimiento adecuado, independiente y transparente para la toma de decisión.

En este marco, los directores no incurrirán en responsabilidad en caso de actuar de conformidad con lo indicado en el párrafo anterior, incluso si finalmente las decisiones que adoptaron no resultaron las más convenientes para la sociedad.

No se entenderán incluidas dentro del ámbito de discrecionalidad empresarial aquellas decisiones que involucren directa o indirectamente a algún accionista, o algún director o gerente y personas vinculadas a estos. En particular, cuando se trata de permitir a estos realizar las operaciones prohibidas por el artículo 150 o cuando se trate de aprobar algún contrato o negocio con un accionista o con una persona o entidad vinculada a este, corresponderá a los directores dejar constancia de que, al tomar la decisión, el directorio ha cumplido con sus deberes de lealtad y diligencia, que el acuerdo adoptado es de beneficio para la sociedad y que se ha dado prioridad al interés." (el énfasis es nuestro).

Esta creación del legislador peruano parecería redundante si tenemos en cuenta el objetivo que cumple la BJR, pero, como veremos más adelante, la falta de

16 Artículo 226. Protección de la discrecionalidad empresarial.

A. En el ámbito de las decisiones estratégicas y de negocio, sujetas a la discrecionalidad empresarial, el estándar de diligencia de un ordenado empresario se entenderá cumplido cuando el administrador haya actuado de buena fe, sin interés personal en el asunto objeto de decisión, con información suficiente y con arreglo a un procedimiento de decisión adecuado.

B. No se entenderán incluidas dentro del ámbito de discrecionalidad empresarial aquellas decisiones que afecten personalmente a otros administradores y personas vinculadas $\mathrm{y}$, en particular, aquellas que tengan por objeto autorizar las operaciones previstas en el artículo 230. 
jurisprudencia sobre la materia y la aparición de sesgos en el análisis judicial justificarían dicha inclusión. Más aún si se busca preservar los efectos positivos de dicha regla, esto es el fomento de una cultura de innovación y una sana asunción y gestión de riesgos empresariales ${ }^{17 .}$

Finalmente, cabe resaltar que los requisitos de aplicación de la BJR son la materialización de los deberes fiduciarios. Así pues, los requisitos (i) y (ii) responden al deber de lealtad (Duty of Loyalty), en tanto refieren al rol que tienen los administradores para con los intereses de la sociedad; mientras que los requisitos (iii) y (iv) responden al deber de cuidado (Duty of Care) en la medida que evocan al cumplimiento de los procedimientos establecidos para la toma de decisiones al interior de la empresa.

\section{El sistema de responsabilidad civil de los administradores en el Perú}

Estando claros respecto a la definición de la BJR y su forma de aplicación, importa analizar cómo esta estructurado el sistema de responsabilidad civil de los administradores en el Perú. Para ello, revisaremos dos (2) grandes cuerpos normativos: (i) la LGS; y, (ii) el Código Civil.

\section{i. Regulación según la Ley General de Sociedades}

A efectos de entender el ámbito de responsabilidad civil de los administradores en el marco de nuestra LGS, conviene entender primero su funcionamiento y cómo, legislativamente, están concebidos sus deberes.

Para ello, debemos tener claro que el art. $152^{\circ}$ de la LGS establece que la administración de las sociedades reposa sobre el directorio y uno o más gerentes, guardando silencio respecto a cómo son sus relaciones al interno de la Sociedad Anónima. Sobre el particular, Jorge Trelles y Alonso Rey señalan que ambos órganos actúan en forma coordinada, siendo que cada uno tiene actividades administrativas específicas:

“Asimismo, podemos señalar que el gerente general ejerce su poder o mandato de una delegación específica o general del directorio o de la junta general. En este sentido, el gerente tiene un marco de actuación determinado por el directorio y las facultades encargadas a éste por los órganos sociales. Es decir, el gerente general, a diferencia del directorio, no tiene voluntad propia en aspectos en los cuales el directorio ha decidido sobre un aspecto, el cual deberá ser ejecutado por el Gerente General."18

17 Comisión de expertos en materia de gobierno corporativo. “Estudio sobre propuestas de modificaciones normativas". Madrid, 14 de octubre del 2013. Fecha de consulta: 18 de enero del 2022.

18 TRELLES CASTRO MENDIVIL, Jorge y Alonso REY BUSTAMANTE. “El Gerente General”. Tratado de Derecho Mercantil. Tomo I: Derecho Societario, Lima: Gaceta Jurídica, 2003, p. 626. 
De esta manera, se concibe legalmente al directorio como el órgano encargado de elaborar las políticas generales de administración de la sociedad, mientras que la gerencia general es el órgano que ejecuta tales políticas en la gestión diaria de la empresa. Y es que si tenemos en cuenta que el directorio es un órgano colegiado y la toma de decisiones en su interior implica un debate e intercambio de ideas importante, se hace necesario que exista un órgano de administración que se encargue de ejecutar dichas decisiones administrativas y asuma la marcha diaria de la sociedad.

Teniendo claro lo anterior, es importante poner de manifiesto que, desde una perspectiva civil, la obligación principal de los administradores - directores y gerentes- es poner a disposición de la sociedad, todo su conocimiento y expertíz a fin de mejorar sus posibilidades de crecer en el mercado. Este deber central, debido a la naturaleza obligacional del vínculo entre la sociedad y sus administradores, se complementa con los llamados deberes accesorios, dentro de los cuáles se encuentran los deberes fiduciarios de lealtad y cuidado desarrollados en la doctrina societaria.

En efecto, en la medida que los daños generados por el incumplimiento de obligaciones de los administradores se analizan bajo el sistema de responsabilidad civil por inejecución de obligaciones, se puede inferir que la relación preexistente es contractual o, cuando menos, de naturaleza obligacional compleja. Esta idea es compartida por Juan Espinoza Espinoza, quien señala lo siguientes:

“(...), parece más persuasivo argumentar que, frente a un daño ocasionado dentro de una relación orgánica (entre el director y la sociedad), la normatividad a aplicarse debe ser la de la responsabilidad contractual, (...) porque [hay] (...) una relación jurídica previamente asumida y dentro de la cual se ha lesionado una particular posición jurídica."19

Al tratarse de una relación contractual u obligacional compleja, importa saber si el administrador le genera una utilidad material a la sociedad (conocida doctrinalmente como obligación de resultados) o inmaterial (conocida en la doctrina como obligación de medios), a fin de determinar la forma en que se manifiesta el deber de diligencia y la manera en que se debe analizar la responsabilidad civil derivada del incumplimiento de dicha obligación.

Como ya se ha descrito, una operación económica es afectada por diversos factores ajenos a la voluntad de los administradores, como la inflación, caídas de bolsa, etc. Entonces, si les exigiéramos resultados materiales a los administradores, estaríamos pidiéndoles que, pese al riesgo inherente del mercado, siempre obtengan ganancias a favor de la sociedad; exigencia que sería imposible de cumplir en la mayoría de los casos. Por tal motivo, consideramos que los

19 ESPINOZA ESPINOZA, Juan. Derecho de la Responsabilidad Civil. Lima: Gaceta Jurídica, 2006, p. 565. 
administradores sólo se encuentran en la posibilidad de garantizar que pondrán todos sus esfuerzos (prestación del deber central) para mejorar la posición de la empresa para recibir ganancias económicas (utilidad inmaterial). De allí que cumplan una obligación de medios y no de resultados, tal y como resalta Francisco Reyes Villamizar: “(...) [1]a legislación no exige una obligación de resultados, sino, más bien, de medios. El director debe poner todo su empeño para lograr que las decisiones administrativas sean adoptadas con pleno conocimiento e ilustración sobre los diversos factores que se relacionan con aquellas." 20

Teniendo en cuenta lo anterior, la diligencia, en estos casos, impone al administrador una serie de deberes destinados a proteger su actividad, en el entendido que aquella es el único medio por el cual satisfará el interés de la sociedad ${ }^{21}$. Sobre el particular, Gastón Fernández Cruz señala lo siguiente:

“Así, si hoy (...) sólo cabe entender a la relación contractual como una relación compleja (...) no debe dudarse que el concepto de diligencia no puede estar limitado a la medida del deber de prestación, sino que, por el contrario, está referido más bien al deber de protección involucrado en la situación jurídica subjetiva compleja de deber (...)

(...) al vincularse necesariamente el deber de protección de la obligación con la utilidad comprometida en el deber central, la ejecución de la diligencia debida no puede significar otra cosa que la no presentación de vicisitud alguna en el cumplimiento del deber central, es decir, el cumplimiento de la obligación." 22 (el énfasis es nuestro)

En virtud de lo anterior, podemos afirmar que el deber de diligencia es un deber accesorio de los administradores que les obliga a realizar todas las acciones necesarias para prevenir situaciones que le impidan el cabal cumplimiento de su deber principal. De allí que dichos deberes de diligencia salvaguarden y/o protejan el interés de la sociedad en las actividades de los administradores, ya que dichas actividades son las que satisfacen íntegramente su interés por tratarse de una obligación de utilidad inmaterial u obligación de medios.

Desde este punto de vista, los denominados deberes fiduciarios son deberes accesorios de diligencia que coadyuvan al cumplimiento de la obligación principal de los administradores y protegen el interés de la sociedad, por lo que importa detenernos en su definición.

A. Los deberes fiduciarios

20 REYES VILLAMIZAR, Francisco. Op. Cit. 193. En doctrina nacional, ver GUERRA CERRÓN, María Elena. Levantamiento del Velo y Responsabilidad de las Sociedades Anónimas. Lima: Grijley, 2009, p. 236.

21 FERNÁNDEZ CRUZ, Gastón. “El deber accesorio de diligencia y la responsabilidad derivada del incumplimiento en las relaciones obligatorias". En Negocio Jurídico y Responsabilidad Civil. Lima: Grijley, 2004, p. 611.

22 FERNÁNDEZ CRUZ, Gastón. Ibd. p. 615. 
Los deberes fiduciarios son deberes accesorios que tienen la función principal de dar pautas de conducta a los administradores para el cumplimiento de sus funciones. Según Francisco Reyes Villamizar23, " $[\mathrm{t}]$ ales deberes apuntan al señalamiento de unas reglas definidas de conducta ante los asociados cuya base fundamental está en la exigencia irrestricta de la buena fe de los directores $(. . .)^{\prime \prime}$.

Tal y como lo menciona el autor colombiano, esta clase de deberes tienen su fundamento en la buena fe y la confianza derivada de las relaciones de agencia existentes entre los socios y los administradores de la sociedad, permitiéndoles a los socios fiscalizar y controlar la actuación de sus administradores ${ }^{24}$.

En ese sentido, la doctrina y legislación comparada reconocen dos (2) deberes fiduciarios: (i) Duty of Care o Deber de Cuidado; y, (ii) Duty of Loyalty o Deber de Lealtad.

a. Deber de cuidado

El deber de cuidado o Duty of Care es aquél deber que tienen los administradores de velar por la protección del patrimonio de la sociedad. Siendo ello así, los administradores deben cumplir con sus funciones bajo la mayor diligencia posible en pos de cuidar los intereses de la sociedad, ya que, al tener decisión con respecto a la política económica societaria, se encuentran en mejor posición para prever los riesgos del mercado y tomar las medidas necesarias para mitigarlos. A nivel nacional, dicho deber de cuidado se encuentra legislado en el art. $171^{\circ}$ de la LGS.

b. Deber de lealtad

Por su parte, el deber de lealtad o Duty of Loyalty implica que el administrador deba actuar en forma leal para con los intereses de la sociedad, es decir, nunca preferir sus intereses sobre los de la compañía. En palabras de Eduardo Polo, “(...) [e]l cargo de administrador se sustenta en una relación de confianza que no es comprensible sin la exigencia de un deber de lealtad frente a la sociedad y frente a sus órganos, no solo la junta general, sino el propio órgano administrativo" 25 .

3 REYES VILLAMIZAR, Francisco. Op. Cit. p. 188.

24 DÍAZ TOLOSA, Regina Ingrid. “Deber de los administradores de no competir con la sociedad anónima que administran". En Revista de Derecho, Vol XX, N 1, 2007, p. 88 http://mingaonline.uach.cl/pdf/revider/v20n1/art04.pdf

25 POLO, Eduardo. "Los Administradores y el Consejo de Administración de una Sociedad Anónima". En Comentario al Régimen Legal de las Sociedades Mercantiles, España: Editorial Civitas, 1992, p. 135. 
La base de este deber radica en la confianza otorgada por la sociedad al administrador para que este, de forma discrecional, dirija la política económica y administrativa de la empresa. Y es que el hecho de nombrar a un tercero ajeno a la sociedad para que la administre implica confianza (i) en que los intereses del administrador son los mismos que los intereses de la sociedad; y, (ii) confianza en la capacidad académica y empresarial del administrador. De allí que estemos de acuerdo con Cándido Paz-Ares cuando menciona lo siguiente:

“(...)hemos resumido las razones que avalan esta política de rigor o severidad en el campo de la lealtad, que se cifran básicamente en estas tres circunstancias: (i) la existencia de fuertes incentivos para la extracción de beneficios privados, que eleva la probabilidad de las conductas desleales; (ii)la insuficiencia de los mecanismos disciplinares o de enforcement que proveen las fuerzas del mercado para reducir las prácticas de self-dealing $\mathrm{y}$, por tanto, la especial necesidad de los remedios legales; $y$, (iii) la poca incertidumbre sobre el juicio de deslealtad, lo cual determina que los costes asociados a los riesgos de error y overcompliance sean escasos." 26

Este deber también se encuentra regulado, en forma general, en el art. $171^{\circ}$ de la LGS, pero coincidimos con Jose Antonio Payet cuando señala que el mismo es concretizado en varios artículos de la LGS27.

Con todo, resulta claro que la LGS le delega la administración y ejecución de la política económica de las sociedades al directorio y/o los gerentes- los administradores-, quienes tienen el deber de administrar la sociedad de la mejor manera posible y cumplir con una serie de deberes accesorios que buscan proteger la utilidad inmaterial de la sociedad. Parte de dichos deberes son los deberes fiduciarios de cuidado y de lealtad, los mismos que están regulados en el $171^{\circ}$ de la LGS y demás artículos de dicha norma.

Ahora bien, el incumplimiento de dichos deberes ocasiona responsabilidad civil en los administradores, siendo que ellos responderán por dolo, culpa inexcusable y/o abuso de facultades conforme el art. $190^{\circ}$ de la LGS. Si bien resulta meridianamente claro lo que se entiende por dolo (tradicionalmente entendido como el incumplimiento intencional y deliberado de las obligaciones) y abuso de facultades (entendido como abuso de derecho y que ocurre cuando se actúa de mala fe, si se ha elegido la manera más gravosa de ejecutar

26 PAZ-ARES, Cándido. “La Responsabilidad de los Administradores como instrumento del Gobierno Corporativo". En Derecho societario, Lima: Ius Et Veritas, 2011, p. 307-308.

27 PAYET PUCCIO, Jose Antonio. Op. Cit. Pp. 89. 
un derecho, entre otros requisitos 28 , no es clara la LGS cuando hace referencia a la culpa inexcusable, por lo que debemos remitirnos al Código Civil para complementar el sistema de responsabilidad civil de los administradores.

\section{ii. Regulación según el código civil}

Antes de reseñar las normas de responsabilidad civil que son aplicables a los administradores de sociedades, conviene precisar que el sistema de responsabilidad civil aplicable es el de inejecución de obligaciones. Esto en la medida que el interés afectado, en este tipo de casos, siempre será el de la sociedad y el mismo es concreto y preexistente a la ocurrencia del daño; características específicas de este sistema de responsabilidad civil, tal y como lo desarrolla Carlo Castronovo: “(...) la responsabilidad relacional es una expresión que es capaz de indicar la violación de la relación obligatoria, bien sea que esta tenga su origen en el contrato, en la ley, o que la violación esté referida al deber de prestación a uno de los deberes accesorios." 29

Una vez determinado lo anterior, debemos recurrir al art. $1319^{\circ}$ del Código Civil para entender el concepto legal de culpa inexcusable: "Artículo 1319.- Incurre en culpa inexcusable quien por negligencia grave no ejecuta la obligación."

Ahora bien, el lector podrá advertir que el texto legal no da una definición de culpa inexcusable, limitándose a equipararla a la negligencia grave. Esta situación hace que coincidamos con Leysser León Hilario cuando dice que "(...) [u]no de los peores artículos de todo el Código Civil es, sin duda, el art. $1319^{\circ} \mathrm{CC}$, donde se plasma un razonamiento circular clamoroso: "incurre en culpa inexcusable quien por negligencia grave no ejecuta la obligación". En otras palabras, culpa inexcusable equivale a negligencia grave. ¿Y qué es negligencia grave? ¿No es acaso culpa inexcusable?"30

Ante la falta de una definición legal de culpa inexcusable, importa revisar qué dice la doctrina sobre el particular. Siguiendo lo desarrollado por múltiples autores, advertimos que la definición de culpa tuvo una connotación netamente éticopsicológica en sus inicios, en el sentido que se imputaba responsabilidad al agente que, voluntariamente, hubiese generado un daño a otro. Al apreciarse como un juicio de desvalor, la culpa era considerada como un error conductual que le precedía una desviación de voluntad, lo cual hacía que el análisis sea realizado en

28 ESPINOZA ESPINOZA, Juan. “Algunas consideraciones respecto de la responsabilidad de los directores y gerentes de una sociedad y el problema del denominado abuso de la mayoría". THEMIS - Revista de Derecho, núm.. 37, Lima, 1999, p. 50.

29 CASTRONOVO, Carlo." La relación como categoría esencial de la obligación y de la responsabilidad contractual". En Estudios sobre la responsabilidad civil. Lima: Legales, 2015, p. 400.

30 LEÓN HILARIO, Leysser. Responsabilidad civil contractual y extracontractual. Material elaborado Leysser León Hilario. Lima: Academia Nacional de la Magistratura, 2016, p. 108. 
cada caso concreto y teniendo en cuenta las cualidades de la persona, el tiempo y el lugar en el que ocurrió el daño.

Bajo este primer esquema, la culpa se manifestaba de dos (2) formas: (i) culpa negligencia, que era entendida como la omisión de los deberes de previsión en una conducta determinada; y, (ii) culpa imprudencia, que ocurre cuando un sujeto actúa sin prever las consecuencias de sus actos ${ }^{31}$.

La industrialización y la consolidación del hombre como nuevo centro del ordenamiento jurídico, posteriormente, generaron que la noción voluntarista de la culpa varíe a lo que conocemos como culpa social u "objetiva". Desde este último punto de vista, el comportamiento del sujeto se analiza mediante su comparación con un parámetro de comportamiento socialmente aceptado, prescindiendo de cualquier evaluación a la psique del victimario ${ }^{32}$ tal y como lo señala Luigi Corsaro: “(...) la culpa se ha transformado en un juicio sobre un comportamiento, es decir, en la afirmación de que un comportamiento es contrario a un modelo ideal, correspondiente al de un hombre cuidadoso en evitar la realización de eventos que puedan lesionar los intereses ajenos protegidos por la ley." 33

Teniendo en cuenta estas definiciones de culpa, y bajo la consideración de que la responsabilidad civil es una institución única de la cual se ramifican los distintos regímenes de responsabilidad, podemos advertir que, en nuestro Código Civil, se ha recogido la valoración subjetiva de la culpa, que es heredada de la noción éticopsicológica de la culpa ${ }^{34}$. Sin embargo, sea que nos sometamos a un concepto subjetivo $u$ objetivo de culpa, la misma siempre nos obligará a realizar comparaciones con un parámetro objetivo de comportamiento en la medida que consideremos a la diligencia como el concepto antitético de la culpa ${ }^{35}$. Dicho esto, la diferencia entre culpa leve y la culpa inexcusable, influenciada por la noción ético-psicológica de la culpa, es bien explicada por Felipe Osterling:

“La culpa grave consistía en no poner los cuidados más elementales, en la más absoluta falta de diligencia. Culpa leve in abstracto era aquella en que incurría quien no prestaba los cuidados de un bonus et diligens pater famlias. $(\ldots)$.

En la culpa leve in concreto se usaba no un tipo ideal o abstracto para comparar, sino al propio deudor. La imputabilidad del deudor se

31 TRIGO REPRESAS, Félix. “Responsabilidad civil de los profesionales”. Citado por FERNÁNDEZ CRUZ, Gastón. "De la culpa ética a la responsabilidad subjetiva: ¿el mito de Sísifo? (Panorámica del concepto y del rol de la culpa en el derecho continental y en el Código Civil peruano)". THEMIS- Revista de Derecho, núm. 50, Lima, 2005, p. 241.

32 COLIN, Ambrosio y CAPITANT, H. Curso Elemental de Derecho Civil, Editorial Reus: Madrid, 1943, p. 824.

33 CORSARO, Luigi. "Culpa y responsabilidad civil: La evolución del sistema italiano", en Estudios sobre Responsabilidad Civil, ARA Editores: Lima, 2001, p. 183.

34 FERNÁNDEZ CRUZ, Gastón. Op. Cit., p. 254, 2005.

35 FERNÁNDEZ CRUZ, Gastón. Op. Cit. Pp. 258, 2005. 
determinaba decidiendo si había puesto o no los mismos cuidados que en sus otros asuntos." 36

Así pues, y atendiendo a lo desarrollado hasta aquí, la culpa leve sería la falta de cumplimiento del comportamiento abstracto jurídicamente exigido al sujeto; mientras que la culpa grave hace referencia a aquellas actuaciones extremadamente negligentes que no cometería ninguna persona, aunque aquella fuese descuidada. En buena cuenta, es la máxima torpeza posible ${ }^{37}$.

Trasladando lo anterior a la responsabilidad civil de los administradores, podremos ver que el modelo de comportamiento abstracto que deben cumplir se encuentra regulado, precisamente, en la LGS, el cual señala que dichos agentes deben desempeñarse en el cargo en forma diligente y conforme lo haría un ordenado y leal comerciante. De esta manera, en principio, los administradores sólo responderían por los daños ocasionados si es que no han cumplido con dicho parámetro de comportamiento.

Si atendemos a la clasificación de culpa leve y culpa inexcusable descrita en el presente trabajo, veremos que la LGS únicamente dispone el parámetro de diligencia ordinaria que los administradores deben respetar en ejercicio de sus funciones (art. $1320^{\circ}$ del Código Civil) (culpa leve). Sin embargo, la LGS expresamente indica que los administradores sólo serán responsables por dolo, negligencia grave (culpa inexcusable) o abuso de facultades, por lo que una lectura integral de la LGS y el Código Civil nos permite concluir que los administradores únicamente serán responsables frente a la sociedad en caso se acredite que sus decisiones empresariales han sido tomadas con una negligencia tan grande que ningún otro administrador en el mercado las hubiese adoptado.

Al respecto, consideramos positivo que los administradores sólo sean responsables por dolo o culpa inexcusable, ya que ello no sólo responde a una política netamente incentivadora de las actividades comerciales, sino que también reconoce la inexistencia de una Lex Artis definida sobre la materia. En efecto, si tenemos en cuenta que los agentes económicos están constantemente expuestos a los riesgos del mercado, los administradores tienen el deber de mitigar estos últimos a fin de evitar el mayor daño posible a la sociedad, pero sin que ello implique una precaución extrema al momento de desarrollar sus operaciones económicas. En ese sentido, con la eximente de culpa leve, se incentiva que los administradores sean innovadores y tomen riesgos en la administración de la sociedad bajo la premisa que sólo responderán por la negligencia grave (un acto o decisión económica que nadie en el mercado haría por ser sumamente torpe) y/o si han tenido la intención de dañar a la sociedad. De allí que Jose Antonio Payet

36 OSTERLING PARODI, Felipe. Inejecución de Obligaciones: Dolo y Culpa. Materiales de enseñanza del Curso "Responsabilidad Civil Contractual y Extracontractual" de la Academia Nacional de la Magistratura, 2016, p. 359.

37 OSTERLING PARODI, Felipe. Ibid. p. 360. 
señale que, en nuestro sistema legal, “(...) no será responsable el administrador por el sólo hecho de que el juez, u otra persona, pudiera pensar que los negocios debieron haberse conducido de una manera diferente. Lo será sólo si prácticamente nadie en su sano juicio hubiera adoptado la decisión que tomó el administrador." 38

En resumen, vemos que la LGS y el Código Civil regulan conjuntamente la responsabilidad civil de los administradores, siendo que la primera define cuáles son los deberes que dichos sujetos deben cumplir en el ejercicio de sus funciones y los criterios de imputación de responsabilidad civil que se seguirán en caso de su incumplimiento (dolo, culpa inexcusable y abuso de facultades); mientras que el segundo, en conjunto con la doctrina civil, define dichos criterios de imputación, determinando que los administradores serán responsables por adoptar decisiones que nadie en su sano juicio tomaría en el mercado (culpa inexcusable), por incumplir intencionalmente sus obligaciones (dolo) y/o abusen de sus facultades (entendido como abuso de derecho).

Si bien estas conclusiones son válidas desde el punto de vista legal y, en principio, la discrecionalidad empresarial de los administradores estaría protegida, también es cierto que la judicatura es proclive a aplicar su propio criterio económico para imputar responsabilidad civil a los profesionales. Por tal motivo, es difícil asegurar que un juez seguirá el razonamiento aquí descrito y resistirá la tentación de aplicar su propio criterio económico como parámetro de actuación "diligente", lo cual inyecta una dosis importante de incertidumbre al análisis de la culpa de los administradores y a la dinámica del mercado en nuestro país.

\section{La viabilidad de la aplicación de la BJR en el Perú}

Habiendo explicado cómo esta regulado el sistema actual de responsabilidad civil de los administradores en el Perú, corresponde analizar si la BJR es compatible con aquél $y$, a su vez, si es necesaria, o no, su implementación en nuestra legislación societaria.

\section{i. Nuestro sistema legislativo es compatible con la BJR}

Como ya hemos visto, el criterio de imputación de responsabilidad civil aplicable a los administradores es, entre otros, la culpa, lo cual implica comparar el comportamiento de los sujetos con un parámetro mínimo de diligencia. En ese sentido, si consideramos que el juez no tiene un parámetro fijo para determinar cuándo un administrador ha incurrido en culpa grave (un concepto subjetivo), vemos entonces que la BJR coadyuvaría a delimitar mejor el análisis, asegurando que el juez no tenga la posibilidad de afectar la discrecionalidad empresarial con sus sentencias.

38 PAYET PUCCIO, José Antonio. Op. Cit. p. 88. 
En efecto, como ya se ha desarrollado, en el Perú la relación existente entre la sociedad y sus administradores es de una naturaleza obligacional compleja, ya que no sólo alberga un deber central (administrar a la sociedad en base a sus conocimientos especializados y experiencia) que brinda utilidad inmaterial a la empresa (la posibilidad de crecer en el mercado), sino que también contiene deberes accesorios (deber de diligencia, deber de cuidado, deber de lealtad entre otros) que los administradores deben cumplir para proteger el cumplimiento del deber central y, a su vez, el patrimonio de la sociedad.

Bajo dicho punto de vista, los administradores cumplen sus deberes para con la empresa con el sólo hecho de ser diligentes en la prestación de sus servicios y no porque haya ocurrido un determinado resultado. Por lo tanto, y en la medida que se haya realizado el encargo de forma diligente y de buena fe, los resultados negativos de las decisiones empresariales de los administradores no deberían ser hechos determinantes para obligarlos a pagar una indemnización en favor de la empresa.

Si tenemos en cuenta que la BJR opera bajo la premisa que los administradores han tomado sus decisiones empresariales en forma diligente y de buena fe, entonces podemos concluir que dicha regla aplica en caso ambos conceptos (diligencia y buena fe) sean los parámetros de conducta abstractos que guíen la actuación de los administradores en el ejercicio de sus funciones. Parámetros que, precisamente, operan en nuestro medio conforme lo establece la LGS y el Código Civil.

Y es que la BJR pone énfasis en la conducta de los administradores y no en el resultado de su gestión; mismo enfoque que se adopta al analizar, en el contexto peruano, la culpa grave de estos sujetos. De allí que, si los jueces peruanos aplicasen la BJR, estarían ratificando que lo importante es verificar la toma diligente de las decisiones empresariales y que el resultado de una operación económica no es un elemento determinante para imputar responsabilidad civil a los administradores; lo cual va acorde con el sistema de responsabilidad civil por inejecución de obligaciones regulado en el Código Civil.

En conclusión, en la medida que la prestación principal de los administradores es la actividad misma de administrar y que el cumplimiento diligente de dicha actividad es suficiente para satisfacer el interés de la sociedad, la aplicación de la BJR en el Perú devendría en legítima y viable, por cuanto la misma protege la discrecionalidad empresarial de los administradores en la medida que se acredite que los mismos han actuado conforme a los parámetros de diligencia establecidos en la LGS y en el Código Civil.

\section{ii. Los problemas que se buscan solucionar con la BJR ocurren en nuestra realidad}

Habiendo determinado que la BJR es compatible con nuestro sistema jurídico, corresponde analizar si es necesaria la aplicación de la misma en nuestro contexto 
legal. En ese sentido, la doctrina39 ha identificado cuatro (4) fundamentos que justificarían la aplicación de la referida regla en un determinado ordenamiento jurídico, a saber: (i) elimina y/o mitiga el riesgo que el juez aplique su criterio económico; (ii) evita los sesgos en el análisis de diligencia de las decisiones empresariales; (iii) protege la innovación y la aversión al riesgo en los negocios; y, (iv) suple la falta de Lex Artis. A continuación, desarrollaremos cada uno de estos fundamentos a la luz de la experiencia peruana.

A. Riesgo del criterio económico del juez y el análisis sesgado de las decisiones empresariales

La experiencia internacional demuestra que la BJR evita que el juez, en base a su criterio económico y una percepción sesgada de los hechos, analice la decisión económica y cuestione el criterio empresarial de los administradores a fin de exigirles una diligencia desmedida que no se condiga con la realidad del mercado.

En efecto, el juez, como toda persona, se encuentra dispuesto a utilizar atajos mentales para resolver los casos a su cargo, siendo que dicho estado mental tiene, como consecuencia, el uso de lo que denominamos sesgos. Un sesgo es un prejuicio que ostenta una persona al momento de analizar un hecho objetivo y que modifica sustancialmente el resultado de dicho análisis. Sobre el particular, André Castro Carvalho afirma lo siguiente:

"Las heurísticas pueden ser definidas como un "atajo mental", que significa una manera de hacer uso de ciertos patrones que resultan en una especie de regla a ser usada en cada caso específico. (...) Sin embargo, esto puede derivarse en algunos errores en la evaluación (...) Así, el uso de la claridad para construir las heurísticas derivará en el conocido sesgo, el cual es un error en el juicio producto de estas repentinas evaluaciones estandarizadas" 40

En consecuencia, el constante uso de atajos mentales derivará necesariamente en el empleo de sesgos al momento de evaluar y/o analizar un hecho de la realidad, modificando sustancialmente la perspectiva que se tiene del mismo. Así, el sesgo que aparece con mayor frecuencia en los jueces es el denominado sesgo de retrospectiva, el cual hace que el operador jurídico, conociendo el resultado de las acciones del sujeto, asuma que dicha persona se encontraba en posición de prever dicho resultado, exigiéndole un mayor grado de diligencia que el legalmente previsto.

El problema con este sesgo, en el caso de la responsabilidad civil de los administradores, radica en que el juez utilizará el resultado objetivo de la

39 GURREA-MARTINEZ, Aurelio. Op. Cit. 420-424.

40 CASTRO CARVALHO, André. "Heurísticas y sesgos en las finanzas públicas y el derecho tributario. Esquemas de un enfoque conductual en Brasil”. En Ius Et Veritas, núm. 43, 2011, p. 294. 
decisión empresarial como punto de partida para analizar el caso cuando lo correcto sería analizar la situación misma del administrador y las posibilidades reales y razonables que éste tenía para tomar las medidas necesarias para mitigar y/o evitar los resultados negativos de su decisión. Y es que, como señala José María de la Jara:

“(...) [e]s más fácil recordar lo que sí sucedió, en comparación a todos los posibles resultados que nunca ocurrieron. Lo que sí pasó está más disponible en la memoria que lo que no. Con ello, tomar el resultado del evento como lugar de partida parece algo natural. No obstante, el problema yace en que la confianza en dicho punto de referencia suele ser exagerada. (...)." 41

Frente a esta situación, la BJR actúa como una regla que previene el sesgo de retrospectiva judicial en el análisis de la responsabilidad civil de los administradores, impidiéndoles cuestionar el criterio económico de dichos agentes a partir del resultado negativo de su gestión. De esta manera, los jueces no tienen la posibilidad de realizar un análisis sesgado del caso y los administradores se ven "liberados" del alto costo que representa este tipo de revisión empresarial judicial.

Teniendo esto en mente, debemos decir que no hemos encontrado jurisprudencia peruana que nos muestre cómo ha sido el razonamiento judicial en materia de responsabilidad civil de los administradores. De allí que no tengamos data que nos confirme la existencia del sesgo anteriormente descrito en los jueces nacionales al momento de analizar la diligencia de estos sujetos en el ejercicio de sus funciones.

Esta falta de jurisprudencia puede obedecer a la forma en que esta legislada la acción social de responsabilidad civil en la LGS. En efecto, nuestra normativa societaria exige una participación importante de acciones (1/3) para plantear una pretensión social de responsabilidad en ausencia del acuerdo de Junta General de Accionistas. Sin embargo, en palabras de Jose Antonio Payet, “(...) la participación en el capital que se exige a la minoría para poder sobreponerse a la oposición del grupo mayoritario es tan elevado, que en la práctica la norma más parece una disposición que garantiza la impunidad de una mayoría calificada que una que protege a una minoría calificada (...). " 42

Lo anterior nos obliga a revisar otras sentencias donde se haya analizado la responsabilidad civil de los profesionales a fin de confirmar nuestra tesis, ya que, en estos casos, al igual que en la responsabilidad civil de los administradores, se analiza si los profesionales fueron diligentes o no. Dicho

41 DE LA JARA, José María. “Condenado por intuición: el cerebro del juez en la determinación del daño y del factor de atribución". En Forseti, núm.. 2, 2014, p. 156-157.

42 PAYET PUCCIO, José Antonio. Op. Cit. p. 90. 
esto, resulta interesante la Casación N²20-2013-LIMA, ya que demuestra claramente cómo los sesgos están presentes en el razonamiento judicial.

En dicho caso, una paciente demandó a su médico tratante y el nosocomio en el que fue atendida debido a que las heridas en su pierna se agravaron, al punto de volverse necróticas, por la mala praxis empleada. En respuesta, los demandados señalaron que siguieron el protocolo de atención establecido y que, en la medida que su obligación es de medios y no de resultados, no había daños que indemnizar en tanto cumplieron en forma diligente su obligación.

La Corte Suprema, en última instancia, revisó el caso y afirmó lo siguiente:

“Quinto.- Que, el supuesto de la norma contenida en el artículo 1762 del Código Civil exige que se trate de problemas técnicos de especial dificultad, supuesto que no se ha presentado en el caso de autos pues el tratamiento a una herida producto de un accidente automovilístico no reviste dificultad y por tanto de presumirse que los médicos especializados tienen la suficiente experiencia para determinar cuándo procede el uso de uno u otro aparato (calza de yeso o férula), $<<$ Así, se colige que, mientras más consolidadas y experimentadas se hallen las técnicas aplicables a un determinado, lo cual genera una relación de correspondencia entre el escrupuloso respeto del protocolo y el éxito de la intervención médica. En cambio, en la medida en que haya incertidumbre sobre los métodos aplicables, o en que se trate de un problema que presente una particular dificultad técnica, la responsabilidad se limitará a los casos en que existe dolo o culpa inexcusable.>>"

Lo anterior nos permite comprobar que los jueces supremos no sólo analizaron el procedimiento realizado por los demandados en el tratamiento de su paciente, sino que lo cotejaron con su "criterio médico" y concluyeron que los demandados eran responsables civilmente por los daños ocasionados derivados de su "mala praxis". De esta manera, somos testigos de cómo los jueces son proclives a analizar los hechos desde un punto de vista sesgado, es decir a partir del resultado dañoso en lugar de hacerlo desde la conducta humana empleada.

En suma, vemos que el sesgo de retrospectiva afecta al análisis de los jueces al momento de aproximarse a un caso de responsabilidad civil profesional, por lo que existen fuertes razones para creer que este sesgo también puede afectar el análisis de responsabilidad civil de los administradores de sociedades. Ello sin perjuicio que nuestra legislación societaria está pensada para proteger la discrecionalidad empresarial de los administradores. De allí que resulte importante la incorporación de la BJR a nuestra legislación societaria en aras de salvaguardar la discrecionalidad empresarial. 
B. Proteger la innovación y la aversión al riesgo en los negocios

Por otro lado, la BJR protege la discrecionalidad empresarial en la toma de decisiones económicas, fomentando la adopción de nuevas formas de negocio y la innovación en el mercado. Desde este punto de vista, la regla en cuestión coadyuvaría al desarrollo del mercado y el perfeccionamiento de las formas de gestión empresarial, cuestiones sumamente relevantes en un mercado cambiante como el peruano.

En efecto, somos testigos de cómo la innovación y el uso de las nuevas tecnologías están cambiando el mercado. Por ejemplo, las empresas que antes se dedicaban exclusivamente al comercio físico, han variado su esquema de negocio para acoplarse al comercio electrónico, siendo que el número de negocios (MYPES y empresas de venta de bienes y servicios) dedicados a e-commerce se incrementó de 65,800 a 263,200 al final del 202043.

Por otro lado, las restricciones y medidas administrativas por Covid-19 han ocasionado que el empresariado peruano haya adoptado nuevas medidas para subsistir, tales como: (i) adecuar el marketing empresarial a las nuevas necesidades del mercado; (ii) redefinir el portfolio de productos y servicios; (iii) liderar procesos de "adelgazamiento" patrimonial o venta de activos y resolución de contratos innecesarios; y, (iv) revisar los modelos predictivos y prospectivos de la demanda del mercado a fin de acoplarlos a la nueva realidad 44 .

Finalmente, no debemos perder de vista que últimamente se han ido creando nuevas condiciones regulatorias para aquellos segmentos del mercado que tienen contacto directo con el consumidor final, tales como las telecomunicaciones ${ }^{45}$, sector bancario 46 y el comercio electrónico ${ }^{47}$. De esta

43 CÁMARA DE COMERCIO ELECTRÓNICO DEL PERÚ (CAPECE). Reporte Oficial de la Industria Ecommerce en Perú. Impacto del Covid-19 en el comercio electrónico en Perú y perspectivas al 2021. Lima, p. 15, 2021.

https:// www.capece.org.pe/wp-content/uploads/2021/03/Observatorio-Ecommerce-Peru2020-2021.pdf

44 MERZTHAL TORANZO, Jorge. El sector B2B frente a los retos de la nueva coyuntura. Fecha de consulta: 19 de abril del 2021.

https://www.esan.edu.pe/conexion/actualidad/2021/03/25/el-sector-b2b-frente-a-los-retosde-la-nueva-coyuntura-3/

45 Por ejemplo, OSIPTEL, a través de la Resolución N 19-2021-CD-OSIPTEL, ha dispuesto que todas las operadoras de telecomunicaciones deben permitir que sus clientes puedan realizar trámites y procedimientos relacionados al servicio mediante una app móvil. Esto, indudablemente, impacta en la estrategia comercial de las operadoras de telecomunicaciones, en la medida que les obliga a digitalizar sus servicios.

46 El 18 de marzo del 2021, el Congreso de la República publicó la Ley № 31143 - Ley que protege de la usura a los consumidores de los servicios financieros, a través del cual facultó al Banco Central de Reserva del Perú (BCRP) para imponer topes máximos a las tasas de interés de operaciones en el sistema financiero.

47 El 7 de octubre del 2021, el congresista José Luna Gálvez presentó el Proyecto de Ley № 415/2021$\mathrm{CR}$, a través del cual propone una serie de modificaciones al Código de Protección y Defensa al Consumidor a fin de proteger al consumidor digital y la seguridad en las transacciones que se realizan mediante el comercio electrónico. A la fecha de redacción del presente texto, el proyecto 
manera, las empresas no sólo tienen que hacer frente a las nuevas necesidades del mercado, sino que también deben cumplir con las nuevas exigencias regulatorias expedidas por el Estado.

Con todo, es claro que nuestro mercado, al igual que la economía internacional, está en pleno proceso de cambio y resulta necesario que las empresas tengan el suficiente ámbito de libertad para diseñar y planificar sus operaciones de la mejor forma posible. Es más, la coyuntura no permite asegurar el éxito de todas las decisiones empresariales que los administradores vayan a tomar, ya que el mercado ha cambiado casi en su totalidad y los modelos de negocios exitosos de ayer no necesariamente son viables hoy en día.

Frente a la situación anteriormente descrita, resulta necesario que los administradores tengan la suficiente libertad para tomar decisiones empresariales innovadoras y riesgosas por el bien de la sociedad; $y$, a su vez, es importante que dichos administradores tengan la certeza que no se les imputará responsabilidad civil por los resultados negativos de su gestión (cuyas probabilidades de ocurrencia han aumentado considerablemente). $\mathrm{Si}$ tenemos en cuenta que la BJR, precisamente, asegura lo anterior, entonces podremos concluir que es necesaria la aplicación de dicha regla en nuestro ámbito nacional.

Si de por sí es peligroso que un juez analice y cuestione el criterio económico de los administradores en el ejercicio de sus funciones, hoy en día lo es más en tanto nos encontramos en un contexto económico donde las empresas necesitan de soluciones innovadoras y riesgosas para subsistir. De allí que aplicar la BJR a nuestra realidad haría que se protejan las decisiones empresariales y, con ello, se incrementen las probabilidades de reflote económico de las compañías.

En conclusión, tenemos que la situación actual del mercado peruano justifica y hace necesaria la aplicación de la BJR en pos de proteger la innovación y la discrecionalidad empresarial; elementos necesarios para la reactivación económica nacional.

C. Falta de Lex Artis

La Lex Artis es un término para hacer referencia a las prácticas comunes de una determinada rama profesional o industria. En otras palabras, es el conjunto de prácticas y condiciones mínimas de seguridad o diligencia que deben cumplirse en determinadas prácticas profesionales. Al respecto, José Caro John define a la Lex Artis de la siguiente forma:

ha sido aprobado por la Comisión de Defensa del Consumidor del Congreso de la República y está pendiente de debate en el pleno. 
“(...) por tratarse de un ámbito carente de una regulación legal, la actuación médica queda regulada por la lex artis, la misma que está conformada por el conjunto de normas técnicas originadas por la práctica profesional, reiterada y permanente y con legitimidad histórica, es decir, normas no escritas, pero con un grado de institucionalización suficiente para vincular y guiar la actuación de un profesional, en este caso, del médico." 48

Si bien el término ha sido desarrollado más profundamente en el ámbito sanitario como un criterio para determinar si los profesionales médicos han sido diligentes, no es menos cierto que el término es de plena aplicación para cualquier otra profesión y/o industria.

Aplicándolo a la administración de empresas, la Lex Artis se configuraría como el mínimo de prácticas y/o medidas de seguridad que deben ser cumplidos por los administradores en ejercicio de sus funciones. De esta manera, dicha Lex Artis serviría de parámetro para verificar si un administrador ha sido, o no, diligente en la toma de decisiones empresariales. Sin embargo, el gran problema que existe en el ámbito empresarial es que, precisamente, la Lex Artis no es uniforme y, por ende, no hay un parámetro establecido de cómo deberían actuar los administradores en el ejercicio de sus funciones. De allí que Alberto Guerra señale que "[n]o existe una lex artis consolidada por la que se pueda comparar una actuación concreta de un administrador. La actividad de los administradores ha de ser innovadora, razonablemente arriesgada y en estado de constante evolución." 49

En el ámbito nacional, ésta falta de Lex Artis se intensifica si tenemos en cuenta nuestro contexto económico y la falta de jurisprudencia que desarrolle las pautas de conducta mínimas que se espera de un administrador diligente. De allí que podemos decir válidamente que, en el Perú y el mundo, no existe una Lex Artis empresarial consolidada, siendo que cada administrador aplica su propio criterio económico al momento de dirigir y gestionar su empresa.

Frente a lo anterior, la aplicación de la BJR vendría a reconocer esta situación y evitaría que el juez impute responsabilidad a los administradores que han actuado bajo un determinado criterio económico, en la medida que dicho criterio o cualquier otro es sólo una manifestación más de la discrecionalidad empresarial de la que gozan dichos agentes.

En conclusión, luego de haber comprobado que cada uno de los fundamentos que justifican la aplicación de la BJR se da en nuestra realidad

48 CARO JOHN, José Antonio. "Sobre la relevancia del protocolo médico para la concreción del riesgo permitido en el aborto terapéutico". En Ius Et Veritas, núm. 36, Lima, 2008, p. 447.

49 GUERRA, Alberto. Op. Cit. 
empresarial, consideramos que la inclusión de dicha regla en nuestra legislación societaria mejoraría el análisis judicial de la responsabilidad civil de los administradores y, con ello, se brindaría mayor seguridad a las inversiones. Más aún si la práctica judicial en otras ramas relacionadas nos hace inferir que los jueces serán proclives a analizar el criterio económico de los administradores desde una óptica sesgada en retrospectiva.

\section{iii. El reconocimiento constitucional del derecho a la libertad económica}

Finalmente, la aplicación de la BJR también ayudaría a proteger, de mejor manera, el derecho constitucional a la libertad de empresa de las sociedades y sus administradores. Esto en la medida de que, si se le permite al juez cuestionar el criterio empresarial de los administradores a fin de imputarles responsabilidad civil, se le estaría permitiéndole el control indirecto de la actividad económica de la sociedad; control que no se encuentra acorde con nuestra carta magna.

En efecto, el derecho a la libertad de empresa se encuentra reconocido en el art. 59 de la Constitución Política del Perú y establece que su ejercicio no debe ser lesivo a la moral, salud o seguridad pública. Respecto a su definición, el Tribunal Constitucional ha señalado que dicho derecho "(...) se define como la facultad de poder elegir la organización y efectuar el desarrollo de una unidad de producción de bienes o prestación de servicios, para satisfacer la demanda de los consumidores o usuarios." 50

Para entender mejor el contenido constitucionalmente protegido de éste derecho, la jurisprudencia y la doctrina constitucional han señalado que el derecho a la libertad de empresa se divide en tres (3) sub-derechos: (i) libertad de constitución, lo cual permite que las empresas puedan adoptar el vehículo de inversión que mejor calce a sus intereses; (ii) libertad de organización y planificación de su actividad, el cual les permite a las empresas el tener plena autonomía para desarrollar su actividad económica bajo sus propios términos; y, (iii) libertad de salir del mercado. De esta manera, la vulneración a cualquiera de estos derechos es también una afectación al derecho constitucional bajo comentario.

En virtud de lo anterior, advertimos que las sociedades anónimas, así como sus administradores, tienen la plena libertad de desarrollar todas las actividades comerciales que, a su criterio, les parezca económicamente rentables, lo cual es la máxima expresión de su derecho a la libertad económica. Al respecto, Walter Gutiérrez Camacho opina lo siguiente: “La libertad de empresa lleva implícito el derecho de inversión, pues es imposible pensar en una empresa si un mínimo de patrimonio económico comprometido. Esta libertad garantiza el derecho que

$50 \quad$ STC N ${ }^{\circ} 0008-2003-\mathrm{AI}$ 
posee el propietario de un capital para colocarlo en el sector económico que estime conveniente y adecuado a sus intereses. (...)." 51 (el énfasis es nuestro).

Siendo ello así, es evidente que el Estado debe de garantizar la libertad económica de las sociedades y de sus administradores, evitando que algún poder público pueda intervenir en forma ilegal en sus decisiones empresariales salvo que su ejercicio afecte algún otro derecho fundamental o normas imperativas y de orden público.

En nuestro caso concreto, podemos observar que las decisiones económicas que pudieran realizar los administradores se encuentran garantizadas por el derecho a la libertad de empresa, otorgándoles la discrecionalidad suficiente para decidir las operaciones que llevarán a cabo en el mercado. De allí que la aplicación de la BJR contribuiría a salvaguardar dicha libertad en sede judicial, en tanto les permitiría adoptar las decisiones económicas que consideren convenientes sin tener la inseguridad que, posteriormente, un juez vaya a evaluar el fondo de dicha decisión como un elemento fundamental para imputarles responsabilidad civil.

No debemos olvidar que la BJR, precisamente, le debe su nacimiento a la idea de evitar que los jueces puedan cuestionar el criterio económico de los administradores a fin de preservar la libertad que tienen las empresas para determinar su propia política económica ${ }^{52}$.

\section{Conclusiones}

Conforme hemos podido desarrollar en el presente trabajo, la BJR es una regla jurisprudencial que evita que los jueces, por ocasión del análisis de responsabilidad civil de los administradores, cuestionen el criterio económico empleado en las decisiones empresariales y tengan en cuenta sus resultados económicos para determinar si un administrador fue diligente o no. De esta manera, en la medida que no se logre demostrar que los administradores tomaron la decisión de mala fe, en conflicto de intereses, sin la información disponible y/o sin haber cumplido con el procedimiento de decisión aplicable, se presumirá que aquellos han actuado en forma diligente y de buena fe, eximiéndolos de responsabilidad civil por los resultados negativos de su gestión.

Dicho esto, consideramos que la incorporación de la BJR al ALGS es justificado y acorde a nuestra realidad jurídica por tres (3) razones específicas. En primer lugar, advertimos que la BJR es compatible con nuestro sistema legal de responsabilidad civil, ya que la misma enfoca el análisis en la actividad diligente del administrador bajo la premisa que su obligación es de medios y no de resultados; esquema que se sigue, o al menos debería seguirse, en nuestro medio nacional al momento de analizar la culpa inexcusable de los administradores. En segundo lugar, comprobamos que los problemas que la BJR previene en el sistema anglosajón

51 GUTIERREZ CAMACHO, Walter. "Comentario al art. 59 de la Constitución Política del Perú". En La Constitución Comentada: un análisis artículo por artículo, Lima: Gaceta Jurídica, 2005, p. 818.

52 Sobre el particular, ver PAYET PUCCIO, José Antonio. Op. Cit. Pp. 87. 
(incentivar la innovación, evitar juicio sesgado del juez y la falta de Lex Artis) están presentes en nuestra realidad económica, por lo que se hace necesaria su implementación a fin de mejorar el estándar de revisión de las actividades empresariales y, con ello, brindarle seguridad jurídica los administradores. En último lugar, la BJR sería una forma de tutelar válidamente el derecho fundamental a la libertad de empresa de los administradores y las sociedades, ya que evita que el juez realice un control indirecto de la actividad corporativa mediante la imposición de su criterio económico como actuación "diligente" y "razonable" en el mercado.

Finalmente, no debemos olvidar que la BJR, al provenir de una tradición y un esquema jurídicos societario distinto al nuestro, debe ser regulado e implementado de la mejor manera y teniendo en cuenta nuestra cultura y contexto nacional. Si bien dicha regla generaría muchas consecuencias positivas, su uso abusivo y desproporcional puede incentivar la adopción de decisiones económicas irracionales que afecten a la sociedad. De allí que sea necesario una implementación uniforme y paulatina de la BJR en aras de preservar sus beneficios y mitigar y/o eliminar sus perjuicios. 